\title{
Studies of the DMP1 57-kDa Functional Domain both in vivo and in vitro
}

\author{
Yongbo Lu Chunlin Qin $^{\mathrm{b}}$ Yixia Xie $^{\mathrm{b}}$ Lynda F. Bonewald ${ }^{\mathrm{a}}$ Jian Q. Feng ${ }^{\mathrm{b}}$ \\ a Department of Oral Biology, School of Dentistry, University of Missouri at Kansas City, Kansas City, Mo., and \\ ${ }^{b}$ Department of Biomedical Sciences, Baylor College of Dentistry, Texas A\&M Health Science Center, Dallas, Tex., USA
}

\section{Key Words}

DMP1 · PHEX • Furin-like proprotein convertase •

Transgenic mice

\begin{abstract}
Dmp1-null mice and patients with mutations in dentin matrix protein 1 (DMP1) resulting in autosomal recessive hypophosphatemic rickets display similar skeletal defects. As mutations were observed in the last 18 amino acids of DMP1 in 1 subset of patients and as fragments of intact DMP1, a 37kDa N-terminal and a 57-kDa C-terminal fragment, have been purified from bone and dentin, we hypothesized that the cleaved 57-kDa C-terminal fragment is the essential functional domain of DMP1. To test this hypothesis, different forms of recombinant DMP1 were expressed in 293EBNA, $\mathrm{CHO}$ and $2 \mathrm{~T} 3$ cells. The results showed that DMP1 was processed into a 37-kDa N-terminal and a 57-kDa C-terminal fragment in vitro in all cell lines examined. DMP1 processing in $\mathrm{CHO}$ cells was blocked by a furin protease inhibitor, decanoyl-Arg-Val-Lys-Arg-chloromethyl ketone, in a dose-dependent manner. Coexpression of PHEX, a potential upstream protease, had no apparent effect on DMP1 cleavage in 293EBNA cells, suggesting that PHEX may not be required for DMP1 processing. To test the in vivo role of the C-terminal fragment, transgenic mice overexpressing full-length DMP1 or the $57-\mathrm{kDa}$ fragment controlled by the $3.6-\mathrm{kb}$ Col1 promoter were generated. Overexpression of these transgenes had no effect on the wild-type skeleton, but on the Dmp1null background showed expression in the osteoblast layer
\end{abstract}

and throughout the bone matrix leading to the rescue of the null bone phenotype. This suggests that the $57-\mathrm{kDa} C$-terminal fragment may be able to recapitulate the function of intact DMP1 in vivo.

Copyright $\odot 2008$ S. Karger AG, Basel

\section{Introduction}

Dentin matrix protein 1 (DMP1), an acidic phosphorylated extracellular matrix protein, was mapped to mouse chromosome 5q21 [George et al., 1994] and human chromosome 4q21:22 [MacDougall et al., 1996]. It is a member of the small integrin-binding ligand, N-linked glycoprotein family that shares similar features in biochemical properties and genomic organization [Fisher et al., 2001]. The Dmpl gene is highly expressed in odontoblasts in tooth and osteocytes in bone, with lower expression in osteoblasts and cartilage [George et al., 1993, 1995; Hirst

\begin{tabular}{ll}
\hline Abbreviations used in this paper \\
\hline BMP1 & bone morphogenetic protein 1 \\
CHO cells & Chinese hamster ovary cells \\
DEC & decanoyl-Arg-Val-Lys-Arg-chloromethyl ketone \\
DMP1 & dentin matrix protein 1 \\
FGF23 & fibroblast growth factor 23 \\
PHEX & $\begin{array}{l}\text { phosphate-regulating gene with homologies to } \\
\text { endopeptidase on the X chromosome }\end{array}$
\end{tabular}


et al., 1997; MacDougall et al., 1998; Toyosawa et al., 2001; Feng et al., 2002].

Although full-length DMP1 cDNA has been cloned and sequenced in several mammalian and nonmammalian species [George et al., 1993; Hirst et al., 1997; MacDougall et al., 1998], the corresponding intact naturally occurring protein has not been isolated from mineralized tissues. However, 2 proteolytic fragments, a $37-\mathrm{kDa} \mathrm{N}$ terminal fragment and a $57-\mathrm{kDa}$ C-terminal fragment, have been purified from rat long bone and dentin extracts, suggesting that these may be the bioactive forms in vivo [Qin et al., 2003]. Phosphate analysis has indicated that the $57-\mathrm{kDa}$ fragment is more highly phosphorylated than the 37-kDa fragment [Qin et al., 2003]. Boskey and her colleagues, using an in vitro cell-free system, showed that the highly phosphorylated $57-\mathrm{kDa}$ fragment purified from rat bone acts as a hydroxyapatite nucleator [Tartaix et al., 2004]. In addition, the 57-kDa fragment contains almost all functional sequences and domains identified to date, including the RGD motif believed to be responsible for mediating cell attachment [Kulkarni et al., 2000], the nuclear localization signal [Narayanan et al., 2003], the ASARM peptide [Rowe, 2004] and the peptide functioning as nucleator [Gajjeraman et al., 2007]. More importantly, it has been discovered that loss of the last 18 amino acid residues of DMP1 results in autosomal recessive hypophosphatemic rickets in humans [Feng et al., 2006]. These observations point to the $57-\mathrm{kDa}$ fragment as the functional domain of DMP1, supporting the hypothesis that full-length DMP1 may be an inactive precursor and that proteolytic processing is an activation step, converting the precursor into functional fragments with distinct yet critical roles in the mineralization of bone and dentin [Qin et al., 2004].

In vivo studies performed in our laboratory suggested that DMP1 plays an essential role in maintaining phosphate homeostasis and in the biomineralization of both teeth and bone. We previously generated Dmp1-null mice, in which exon 6 was replaced by the $\beta$-galactosidase gene [Feng et al., 2003]. These mice postnatally develop characteristics similar to the Hyp mouse, a murine homologue of human X-linked hypophosphatemia, such as the skeletal abnormalities of rickets and osteomalacia as well as similar serum biochemical profiles of elevated circulating serum fibroblast growth factor 23 (FGF23) levels accompanied by hypophosphatemia [Ling et al., 2005; Ye et al., 2005; Feng et al., 2006]. The phenotype of the Hyp mice is caused by a spontaneous $3^{\prime}$-deletion of the phosphate-regulating gene with homologies to endopeptidase on the X chromosome (Phex) [Eicher et al., 1976; Beck et al., 1997]. PHEX is a member of the M13 family of type II transmembrane zinc-containing metalloendopeptidases [Tenenhouse and Sabbagh, 2002; Quarles, 2003].

FGF23 is a potent phosphaturic hormone that is produced by bone and regulates phosphate homeostasis and vitamin D metabolism in the kidney [Liu et al., 2003; Bai et al., 2004; Larsson et al., 2004; Shimada et al., 2004a, b]. PHEX has long been thought to be the protease involved in the processing/degradation of FGF23. Evidence in support of the direct enzyme-substrate relationship between FGF23 and PHEX has been controversial [Bowe et al., 2001; Campos et al., 2003; Liu et al., 2003; Benet-Pages et al., 2004], yet accumulating evidence tends to support the hypothesis that PHEX most likely directly or indirectly regulates FGF23 expression in bone [Liu et al., 2003, 2006]. The inactivating mutation of Phex in Hyp mice could be responsible for increased FGF23 expression in bone responsible for elevated circulating FGF23 levels [Liu et al., 2003]. Both PHEX and DMP1 are mainly and highly expressed in osteocytes [Miao et al., 2001; Toyosawa et al., 2001; Feng et al., 2002, 2003]. This colocalization of DMP1 and PHEX in bone suggests that PHEX may be the proteinase involved in the processing of DMP1. Therefore, it is tempting to propose that PHEX mediates cleavage of DMP1 into its active form and that this active DMP1 fragment then controls phosphate metabolism by regulating FGF23 expression.

In this study, we show that DMP1 is processed into $37-\mathrm{kDa}$-terminal and $57-\mathrm{kDa}$ C-terminal fragments in vitro. Although PHEX has been thought to be the protease responsible for DMP1 cleavage, the coexpression of PHEX in 293EBNA cells had no apparent effect on DMP1 cleavage. Rather, it was found that the processing of DMP1 in Chinese hamster ovary $(\mathrm{CHO})$ cells was blocked by the protease inhibitor decanoyl-Arg-Val-Lys-Argchloromethyl ketone (DEC) in a dose-dependent manner, suggesting that a furin-like proprotein convertase is involved in DMP1 cleavage to generate the active $57-\mathrm{kDa}$ $\mathrm{C}$-terminal fragment. These theories are also being tested in vivo by targeted expression of either full-length DMP1 or the $57-\mathrm{kDa}$ C-terminal fragment in Dmp1-null mice. Preliminary observations suggest that the $57-\mathrm{kDa}$ fragment is the primary functional domain of DMP1.

\section{Materials and Methods}

Plasmids

The coding region of the full-length DMP1 has been previously used to generate transgenic mice under control of a $3.6-\mathrm{kb}$ type I collagen promoter [Lu et al., 2007], and was subcloned into 
the EcoRI site of the pCDNA3 expression vector, giving rise to a pCDNA3-DMP1 expression construct. Based on the cleavage sites identified in rat DMP1, we designed 2 C-terminal $57-\mathrm{kDa}$ fragments: the 2 fragments differ in length by 45 amino acid residues. For generation of the pCDNA3 $-57^{\mathrm{L}}$ construct, expressing the long $57-\mathrm{kDa}$ fragment, and the $\mathrm{pCDNA} 3-57^{\mathrm{S}}$ construct, expressing the short $57-\mathrm{kDa}$ fragment, a DNA sequence, consisting of the gene segment encoding DMP1 signal peptide (16 amino acid residues) in frame with the gene segment encoding the $\mathrm{N}$ terminus of each fragment was cloned into the pCDNA3 expression vector, downstream of the CMV promoter. The long $57-\mathrm{kDa}$ fragment was then subcloned into a mammalian expression vector [Lu et al., 2007] containing the 3.6-kb rat type I collagen promoter plus a 1.6-kb intron 1 at EcoRV and SalI sites, giving rise to the Col1a1-57K transgene. For generation of the pCDNA3-37K construct expressing the short $37-\mathrm{kDa} \mathrm{N}$-terminal fragment, a DNA sequence encoding DMP1 signal peptide and the short $37-$ $\mathrm{kDa}$ fragment was cloned into the pCDNA3 expression vector, downstream of the CMV promoter. A DMP1 construct with the cleavage site mutated at D197A (numbered if the signal peptide was excluded) was subcloned into the EcoRI site of the pCDNA3 expression vector, giving rise to the pCDNA3-mDMP1 construct. The murine PHEX cDNA (kindly provided by Dr. Shiguang Liu at Kansas University Medical Center, Kansas City, Kans., USA) has been previously used to overexpress PHEX in osteoblasts in transgenic mice [Liu et al., 2002]. The PHEX cDNA was subcloned into the EcoRV and XbaI sites of pCDNA3, termed pCDNA3-PHEX. All DMP1 expression constructs were confirmed by a combination of restriction enzyme digestion and DNA sequencing (ABI model 377) at the biotechnology support facility at the Kansas University Medical Center, Kansas City, Kans., USA.

\section{Cell Culture and Transfection}

293EBNA cells, a human kidney cell line, and CHO cells, derived from Chinese hamster ovary, were obtained from the American Type Culture Collection. Both types of cells were cultured in Dulbecco's modified Eagles's medium (with $4.5 \mathrm{~g} / \mathrm{l} \mathrm{D}$-glucose, L-glutamine and sodium pyruvate; Mediatech Inc., Herndon, Va., USA) supplemented with $10 \%$ fetal bovine serum (Invitrogen, Carlsbad, Calif., USA). The osteoblast cell line 2T3, derived from transgenic mice expressing SV40 large T antigen under the control of the osteocalcin promoter (a gift from Dr. Stephen E. Harris, University of Texas Health Science Center at San Antonio, San Antonio, Tex., USA), was maintained in minimal essential medium, $\alpha$-modified Eagle's medium, supplemented with $10 \%$ fetal bovine serum, $100 \mathrm{IU} / \mathrm{ml}$ penicillin and $100 \mu \mathrm{g} / \mathrm{ml}$ streptomycin. Transfection was done using Lipofectamine 2000 reagents (Invitrogen) according to the manufacturer's instructions. All cell cultures were incubated at $37^{\circ} \mathrm{C}$ in a humidified $5 \% \mathrm{CO}_{2}$ atmosphere.

Assessment of DMP1 Processing in Various Cell Lines in vitro To determine the DMP1 processing in vitro in cell lines, various forms of recombinant DMP1, including the pCDNA3 expression constructs, encoding either full-length wild type, mutant DMP1, a 37-kDa N-terminal fragment, or a 57-kDa-long or -short form of the C-terminal fragment, were transiently transfected into 293EBNA, CHO or 2T3 cells. For assessment of DMP1 cleavage by PHEX, 293EBNA cells were transiently co- transfected with $1.5 \mu \mathrm{g}$ of full-length DMP1 or $57-\mathrm{kDa}$ C-terminal fragment expression constructs with either $1.5 \mu \mathrm{g}$ of pCDNA3 empty constructs or $1.5 \mu \mathrm{g}$ of native PHEX expression constructs. For DMP1 cleavage inhibition, CHO or 2T3 cells were transiently transfected with $3 \mu \mathrm{g}$ of pCDNA3 vector, pCDNA-mDMP1, pCDNA3-57K or pCDNA-DMP1 constructs. Twenty-four hours after transfection, the medium was replaced with serum-free medium with addition of $0,5,10,20,40$ or 50 $\mu \mathrm{M}$ of DEC (BIOMOL International, Plymouth Meeting, Pa., USA), a furin-like proprotein convertase inhibitor, for $48 \mathrm{~h}$. The growth medium was replaced with serum-free medium $24 \mathrm{~h}$ after transfection and the transfected cells were further cultured for an additional $48 \mathrm{~h}$. The conditioned medium was collected and centrifuged at $14,000 \mathrm{~g}$ for $15 \mathrm{~min}$ to remove cells and cellular debris. The cell layers were washed with ice-cold PBS, and lysed with radioimmunoprecipitation assay buffer, containing

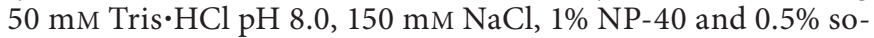
dium deoxycholate, and $0.1 \%$ SDS, supplemented with protease inhibitors, phenylmethanesulfonyl fluoride $0.1 \mathrm{~mm}$ (Sigma-Aldrich, St. Louis, Mo., USA), leupeptin $10 \mu \mathrm{M}$ (Sigma-Aldrich) and pepstatin $1 \mu \mathrm{M}$ (Sigma-Aldrich). The cell lysates were centrifuged at $14,000 \mathrm{~g}$ for $15 \mathrm{~min}$. Recombinant DMP1 proteins in conditioned media or cell lysates were analyzed with Stains-All staining or Western immunoblotting.

SDS-PAGE, Stains-All Staining and Western Immunoblotting The conditioned media or cell lysates were electrophoresed using 4-20\% gradient polyacrylamide gels (Life Gels, Frenchs Forest, NSW, Australia). Recombinant DMP1 proteins were visualized with Stains-All staining as described previously [Qin et al., 2003] or Western immunoblotting using affinity-purified rabbit anti-mouse DMP1 peptide polyclonal antibody 784 against the N-terminal peptide aa100-aa120 (GLGPEEGQWGGPSKLDSDEDS) and antibody 785 against the C-terminal peptide aa469aa483 (AYHNKPIGDQDDNDC), at a dilution of 1:4,000. Recombinant PHEX was immunoblotted with the $13 \mathrm{~B} 12$ anti-PHEX monoclonal antibody (kindly provided by Enobia Pharm Inc., Montreal, QC, Canada), as described previously [Ruchon et al., 2000]. The blot was then incubated with horseradish peroxidaseconjugated goat anti-rabbit secondary antibody (Bio-Rad, Hercules, Calif., USA) diluted to 1:10,000 in $15 \mathrm{ml}$ of 5\% Bio-Rad milk in $1 \times$ TBST for a minimum of $1 \mathrm{~h}$. Immunostained bands were visualized using ECL ${ }^{\mathrm{TM}}$ Chemiluminescent Western Blotting Detection Reagents (Amersham Biosciences, Pittsburgh, Pa., USA), according to the manufacturer's instructions. Chemiluminescent bands were imaged using a CL-XPosure film (Pierce Biotechnology Inc., Rockford, Ill., USA).

Generation of Colla1-DMP1 and Colla1-57K Transgenic Mice

To test the function of the $57-\mathrm{kDa}$ C-terminal fragment in vivo, 2 different transgenic mice were generated to express either a full-length DMP1, Colla1-DMP1 or the long form of the 57$\mathrm{kDa}$ fragment, Colla1-57K, using the same $3.6-\mathrm{kb}$ Colla1 promoter, a promoter highly active in the osteoblast lineage. Colla1DMP1 transgenic mice were generated on a C57B/L6 genetic background at the University of Texas, Houston, Tex., USA and have been described earlier [Lu et al., 2007]. Colla1-57K transgenic mice were generated similarly on a C57B/L6 genetic background. The transgenic mice were screened by PCR analysis using DNA extracted from tail biopsy as previously described [Lu 


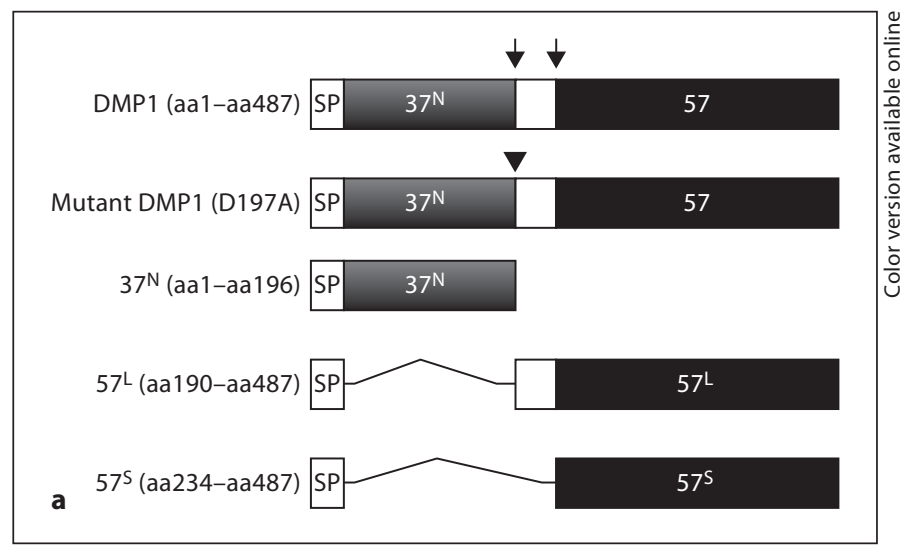

Fig. 1. Schematic representation of DMP1 expression constructs as well as Stains-All staining and Western blot analysis of recombinant DMP1. Full-length DMP1, cleavage site mutated at D197A, $37-\mathrm{kDa} \mathrm{N}$-terminal fragment (aa1-aa196) $\left(37^{\mathrm{N}}\right)$ as well as long $\left(57^{\mathrm{L}}\right)$ and short $\left(57^{\mathrm{S}}\right)$ forms of $57-\mathrm{kDa} \mathrm{C}$-terminal fragment (aa190-aa487 and aa234-aa487, respectively) were cloned downstream of the CMV promoter in the pCDNA3 expression vector (a). The endogenous DMP1 signal peptide aa1-aa16 (MKTVILLVFLWGLSCAL) was linked to both $57-\mathrm{kDa}$ fragments. Various pCDNA3-DMP1 expression constructs, including pCDNA3 vector (E), full-length DMP1 (FL), mutant (M), 37-kDa N-terminal fragment $\left(37^{\mathrm{N}}\right)$ as well as long and short forms of $57-\mathrm{kDa} \mathrm{C}$-terminal fragment $\left(57^{\mathrm{L}}\right.$ and $57^{\mathrm{S}}$, respectively) were transiently transfected into expression cell line 293EBNA cells using Lipofectamine 2000 reagent (Invitrogen). $24 \mathrm{~h}$ after transfection, the medium was replaced by serum-free medium and cultured for an additional 48 h. $20 \mu \mathrm{l}$ of conditioned medium was loaded on a $4-20 \%$ gradient gel and the proteins were visualized with Stains-All staining (b) or detected by Western blot (c) using antibody 784, which recognizes both the full-length DMP1 as well as the $37-\mathrm{kDa}$ N-terminal fragment, or antibody 785, which recognizes both the full-length DMP1 as well as the $57-\mathrm{kDa}$ C-terminal fragment.
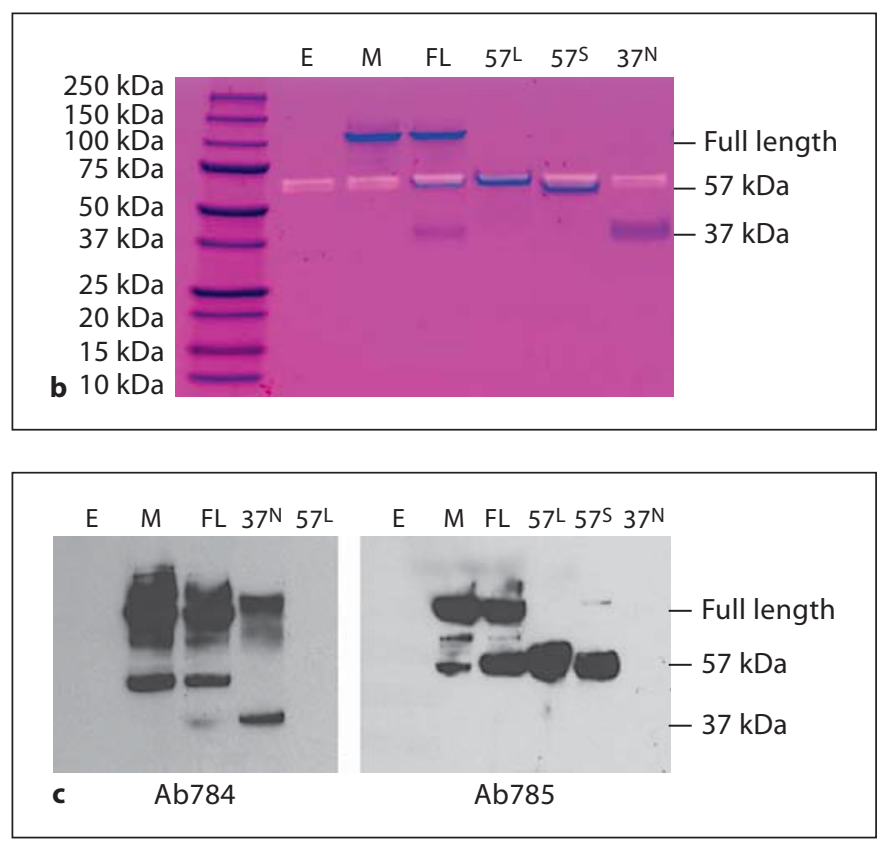

et al., 2007]. Two of four independent Colla1-DMP1 transgenic mouse lines and 3 of 10 independent Colla1-57K transgenic mouse lines were partially characterized and crossed to Dmp1null mice for rescue studies (see below). The animal use protocol was reviewed and approved by the Institutional Animal Care and Use Committee of the University of Missouri at Kansas City, Kansas City, Mo., USA.

Expression of the Col1a1-DMP1 or Colla1-57K Transgene in Dmp1-null Mice

We have previously described the breeding strategy to introduce the Colla1-DMP1 transgene into Dmp1-null mice for reexpression of full-length DMP1 in mice lacking DMP1 [Lu et al., 2007]. Briefly, female Colla1-DMP1 transgenic mice were first crossed with homozygous male Dmp1-null mice (viable and fertile) to generate female mice heterozygous for both

Colla1-DMP1 transgene and Dmp1 gene, Colla1-DMP1 ${ }^{+/}$; $\mathrm{Dmpl}^{+/-}$. The double heterozygous female mice were further bred with Dmp1-null males to produce Dmp1-null mutants carrying the transgene, $\mathrm{Dmp1}^{-/-}$; Colla1-DMP1 $1^{+/-}$. The same breeding strategy was used to introduce the Colla1-57K transgene into Dmp1-null mice to generate Dmp1-null mutants carrying the transgene, Dmp1 ${ }^{-/-}$; Colla1-57 $\mathrm{K}^{+/-}$. The Dmp1-null mice as well as Dmp1-heterozygous mice are being used as the controls.

\section{High-Resolution Radiography}

The bone samples from Colla1-DMP1 or Colla1-57K transgenic mice as well as control mice were dissected free of muscle. The dissected bones were X-rayed on a Faxitron model MX-20 Specimen Radiography System with a digital camera (Faxitron X-Ray Corp., Buffalo Grove, Ill., USA). 


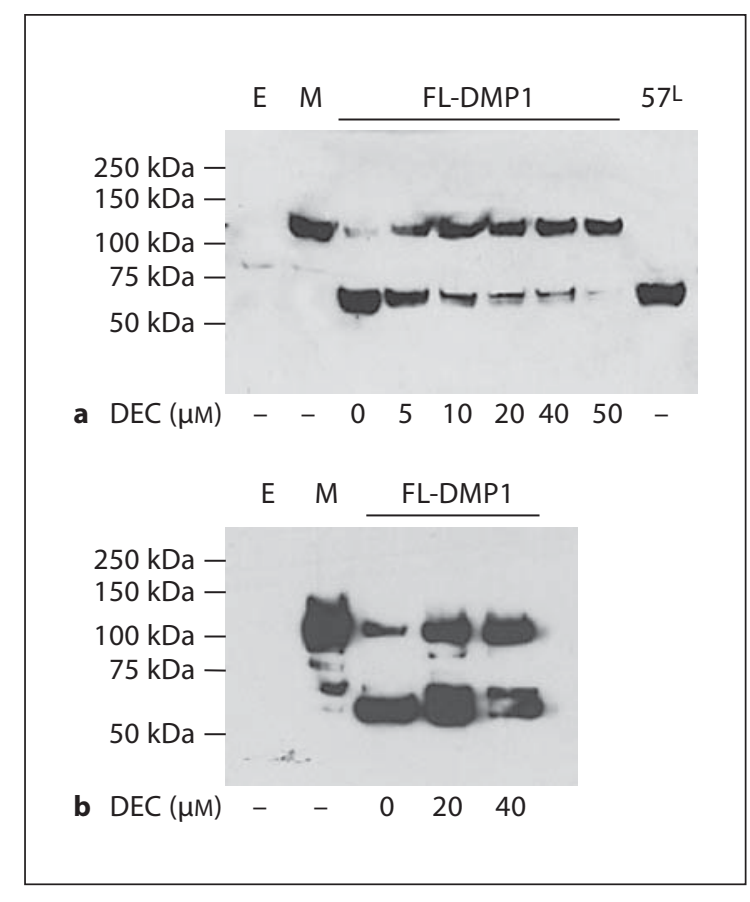

Fig. 2. Effects of DEC, a specific furin inhibitor, on DMP1 processing in $\mathrm{CHO}$ and $2 \mathrm{~T} 3$ cells. $\mathrm{CHO}(\mathbf{a})$ or $2 \mathrm{~T} 3$ cells (b) were transfected with pCDNA3 vector, pCDNA-mDMP1, pCDNA-DMP1 or pCDNA3-57K constructs. $24 \mathrm{~h}$ after transfection, the medium was replaced with serum-free media containing either $0,5,10,20$, 40 or $50 \mu \mathrm{M}$ of DEC. $48 \mathrm{~h}$ later, the conditioned medium was harvested and analyzed by Western blot analysis using the DMP1 C-terminal antibody (785). $\mathrm{E}=$ pCDNA3 empty vector; $\mathrm{M}=$ pCDNA3-mDMP1, the cleavage site mutated at D197A; FLDMP1 = pCDNA3-DMP1, expressing full-length DMP1; 57 $=$ pCDNA3-57K, expressing the DMP1 57-kDa C-terminal fragment.

In situ Hybridization and Immunohistochemistry

The expression of either Colla1-DMP1 or Colla1-57K transgene was analyzed in Dmp1-null mouse tibiae from 3-week-old mice by in situ hybridization and immunohistochemistry. Thereby, any signal generated by either method should reflect the level of transgene expression in Dmp1-null background. In situ hybridization was performed using digoxigenin-labeled DMP1 cRNA probe prepared from a 1.1-kb murine DMP1 cDNA fragment with an RNA Labeling Kit (Roche, Indianapolis, Ind., USA). The 1.1-kb cDNA fragment was obtained by PCR using the full-length DMP1 cDNA as a template with the following primers: forward primer, 5'-CTCCGCAGACACCACACAGTCC-3'; reverse primer, 5' TAGCCGTCCTGACAGTCATTGTC-3'. In situ hybridization on paraffin sections was carried out essentially as described previously [Feng et al., 2002]. Immunostaining of DMP1 protein was performed as described previously [Lu et al., 2007] using the same DMP1 antibodies, 784 and 785, described in Western blot analysis.

Generation of 3.6-kb Colla1-DMP1 and

57-kDa Transgenic Mice

\section{Results}

In vitro Cleavage of Recombinant Full-Length DMP1 into Fragments of the Expected Size

Although the intact native full-length DMP1 has not been isolated from the mineralized tissues, 2 proteolytic fragments, a $37-\mathrm{kDa} \mathrm{N}$-terminal fragment and a $57-\mathrm{kDa}$ C-terminal fragment, have been isolated from rat long bone and dentin extracts, suggesting that DMP1 might be processed into 2 fragments in vivo [Qin et al., 2003]. To test the cleavage hypothesis, various forms of DMP1 expression constructs were made (fig. 1a), including a recombinant full-length DMP1, a full-length DMP1 with a cleavage site mutated at amino acid 197 (D to A), a 37-kDa $\mathrm{N}$-terminal fragment (aa1-aa196) and 2 different forms of the 57-kDa C-terminal fragment (aa190-aa487 and aa234-aa487). Both $57-\mathrm{kDa}$ fragments used the native DMP1 signal peptide, aa1-aa16 (MKTVILLVFLWGLSCA).

Stains-All staining was used to visualize the various forms of recombinant DMP1 expressed in 293EBNA cells (fig. 1b), since DMP1 is a highly acidic phosphorylated extracellular matrix protein. Stains-All stains phosphorylated proteins blue, while the nonphosphorylated proteins and background are stained pink (see online version for color figure). It is of note that lane $\mathrm{E}$ of the conditioned medium from the 293EBNA cells expressing the pCDNA3 empty vector has no blue bands. The recombinant DMP1 containing the single cleavage site mutation was not cleaved as expected. The intact full-length recombinant DMP1 was processed into 37and $57-\mathrm{kDa}$ fragments similar in size to the recombinant 57-kDa C-terminal fragment (both $57^{\mathrm{L}}$ and $57^{\mathrm{S}}$ ) and the $37-\mathrm{kDa} \mathrm{N}$-terminal fragment $\left(37^{\mathrm{N}}\right)$. The size of the recombinant long form of the $57-\mathrm{kDa}$ C-terminal fragment $\left(57^{\mathrm{L}}\right)$ was almost identical to the cleaved $57-\mathrm{kDa}$ fragment from the recombinant full-length DMP1. These findings suggest that in 293EBNA cells the recombinant DMP1 was processed at or close to the conserved cleavage site.

The results from Stains-All staining were further confirmed by Western blot analysis using antibody 784, which recognizes the $37-\mathrm{kDa} \mathrm{N}$-terminal fragment as well as full-length DMP1, and antibody 785 , which recognizes the $57-\mathrm{kDa}$ C-terminal fragment as well as fulllength DMP1 (fig. 1c). Antibody 784 did not react with the cleaved $57-\mathrm{kDa}$ fragment and antibody 785 did not react with the cleaved $37-\mathrm{kDa}$ fragment, validating the cleaved fragments as being either the amino- or carboxyterminal fragments and showing that there was no cross- 


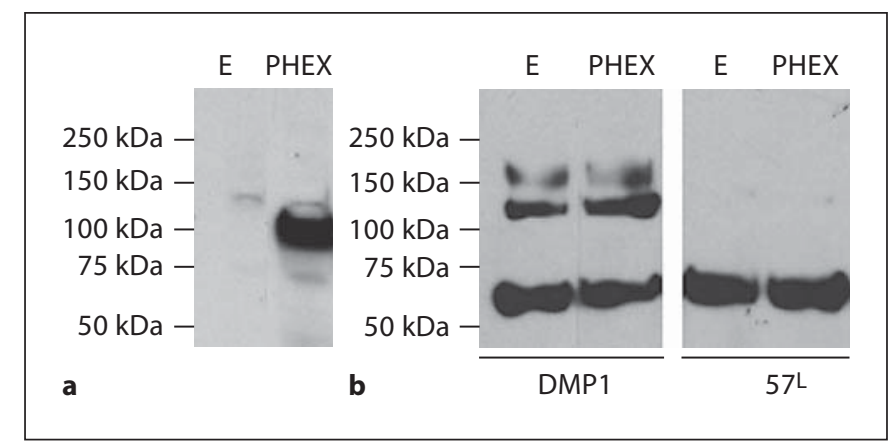

Fig. 3. Coexpression of PHEX and DMP1 in 293EBNA cells. a 293EBNA cells were transfected with either pCDNA empty vector or pCDNA3-PHEX and conditioned media applied to SDSPAGE and the membrane was probed with the 13B12 anti-PHEX monoclonal antibody to detect recombinant PHEX. b Conditioned media from 293EBNA cells cotransfected with combinations of pCDNA3-DMP1 or pCDNA3-57K, or pCDNA3 vector with pCDNA3-PHEX was applied to SDS-PAGE for Western blotting. The blot was probed with DMP1 antibody 785 to detect both the full-length DMP1 as well as the $57-\mathrm{kDa} \mathrm{C}$-terminal fragment. $\mathrm{E}=$ pCDNA3 empty vector; $\mathrm{PHEX}=$ pCDNA3-PHEX, expressing PHEX; DMP1 = pCDNA3-DMP1, expressing full-length DMP1; $57^{\mathrm{L}}=$ pCDNA3-57K, expressing the DMP1 $57-\mathrm{kDa}$ C-terminal fragment.

reactivity between the 2 antibodies. Recombinant DMP1 was also processed similarly in $2 \mathrm{~T} 3$ cells, an osteoblastic cell line, and completely cleaved in CHO cells, as shown by Western blot analysis (see below), suggesting that this cleavage may not be unique to cells that undergo mineralization.

Furin-Like Proprotein Convertase Activity Is Required for DMP1 Processing

Mammalian furin-like proprotein convertases are calcium-dependent serine proteases involved in the endoproteolytic cleavage of precursor proteins to yield biologically active polypeptides [Bergeron et al., 2000]. Furin, a member of this family, has a ubiquitous tissue distribution and exists in 2 forms, a membrane and a shed form [Denault et al., 2002]. It has been demonstrated that furin can process a large number of precursor proteins in the trans-Golgi network/biosynthetic pathway and/or extracellularly within the extracellular matrix [Denault et al., 2002]. DEC is a potent inhibitor of furin-like proprotein convertases, inhibiting the cleavage of proprotein convertase substrates [Denault et al., 1995].

As DMP1 cleavage is apparently not tissue specific, experiments were performed to determine whether a furin- like proprotein convertase is involved in DMP1 processing. Figure $2 \mathrm{a}$ shows the processing of DMP1 in the presence/absence of DEC. First, the cleavage efficiency of full-length DMP1 was compared to that of mutant DMP1 with a cleavage site mutated at amino acid residue 197 (D to A) in the absence of DEC. Western blot analysis showed that more than $95 \%$ of full-length DMP1 is cleaved in CHO cells with transient transfection of the CMV-DMP1 construct. In contrast, more than $99 \%$ of the mutated DMP1 remains intact, suggesting that the aspartic residue at position 197 is critical for DMP1 processing. Subsequently, the same experiment was performed in the presence of DEC at different concentrations. DEC inhibited DMP1 processing in a dose-dependent manner. At $5 \mu \mathrm{M}$, more than $40 \%$ of cleavage is inhibited; at $50 \mu \mathrm{M}, \mathrm{DMP} 1$ cleavage is completely blocked. Similarly, DMP1 processing was blocked by DEC in $2 \mathrm{~T} 3$ cells, an osteoblast cell line (fig. 2b). These observations suggest that a furin-like proprotein convertase directly or indirectly processes DMP1.

\section{PHEX Does Not Cleave DMP1 in vitro}

Dmp1-null mice and Hyp mice manifest similar hypophosphatemic rickets/osteomalacia-like phenotypes. As PHEX is a type II transmembrane zinc-containing endopeptidase [Tenenhouse and Sabbagh, 2002; Quarles, 2003] and DMP1 is processed into a $37-\mathrm{kDa} \mathrm{N}$-terminal fragment as well as a $57-\mathrm{kDa}$ C-terminal fragment both in vivo [Qin et al., 2003] and in vitro, experiments were performed to determine the possible role of PHEX in the cleavage of DMP1 into its active fragments. 293EBNA cells were cotransfected with either full-length DMP1 or 57-kDa C-terminal fragment expression constructs and a native PHEX expression construct (fig. 3). A proportion of the full-length DMP1 was processed into a $57-\mathrm{kDa}$ C-terminal fragment in the absence of PHEX, and coexpression of native PHEX had no effect on the processing of DMP1. In addition, PHEX does not further process 57$\mathrm{kDaC}$-terminal fragment either. This result suggests that DMP1 cleavage is independent of PHEX.

\section{Overexpression of a Full-Length DMP1 or a $57-k D a$ \\ $C$-Terminal Fragment Using the 3.6-kb Colla1-DMP1 \\ Transgene Has No Effect on the Skeleton}

Figure 4 shows the constructs used for the generation of mice expressing the full-length or the $57-\mathrm{kDa}$ fragment, Colla1-DMP1 or Col1a1-57K, respectively, under the control of the $3.6-\mathrm{kb}$ type I collagen promoter. Although Dmp1 ablation in mice results in profound skeletal abnormalities postnatally [Ling et al., 2005; Ye et al., 2005], transgenic mice overexpressing either transgene 


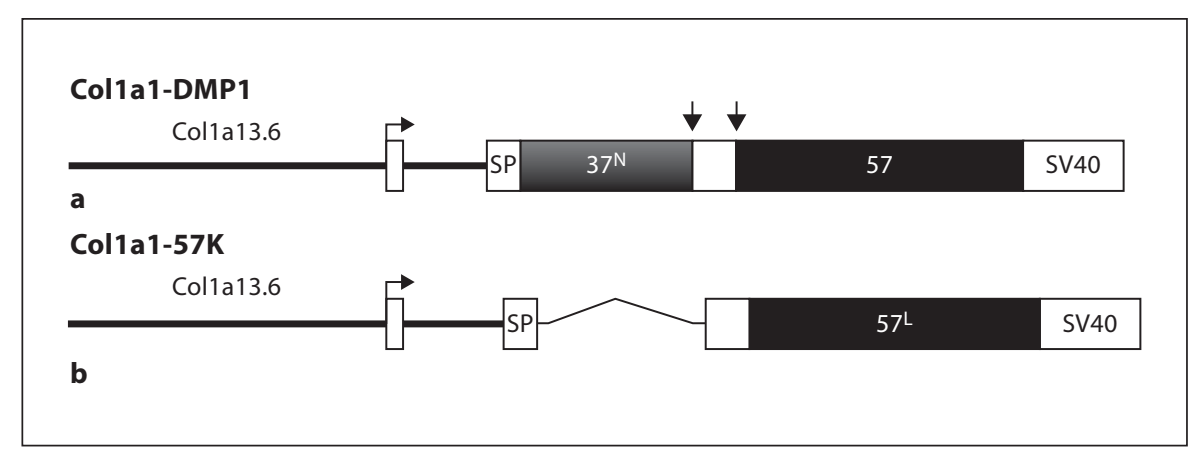

Fig. 4. Constructs used for the generation of full-length and $57-\mathrm{kDa}$ fragment overexpression and rescue transgenic mice. The rat Colla1 promoter was used to drive either the full-length DMP1 cDNA, Colla1-DMP1 (a), or a cDNA fragment encoding the 57-kDa-long C-terminal fragment, Colla1-57K (b). The rat Colla1 promoter includes 3.6-kb 5'-flanking region, first exon and first intron [Kalajzic et al., 2002]. The transcription start site is indicated by the left arrow. The Colla1-DMP1 transgene has been described earlier [Lu et al., 2007], and the Colla1-57K transgene was used for generation of transgenic mice in this study. The signal peptide (SP) was in frame with the $57-\mathrm{kDa}$ fragment to ensure the secretion of the $57-\mathrm{kDa}$ fragment. The downward arrows indicate the 2 potential cleavage sites.

Overexpression of full-length DMP1

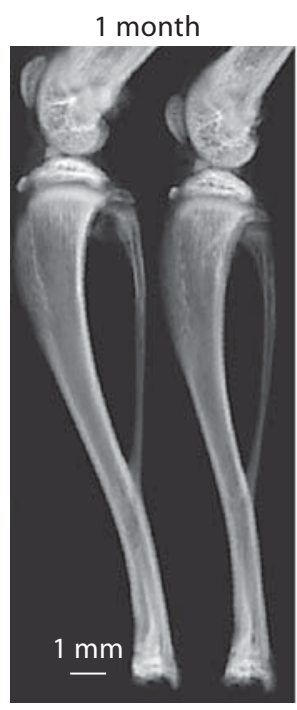

a

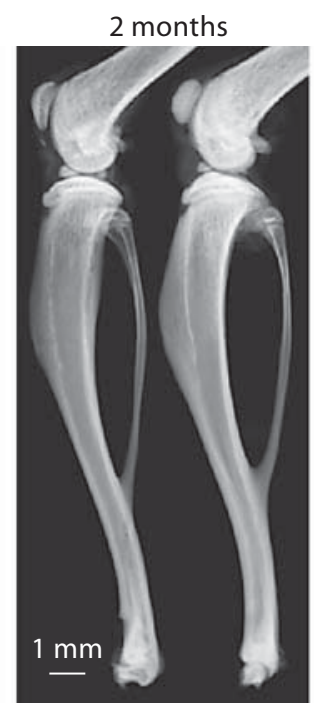

HET + DMP1 HET

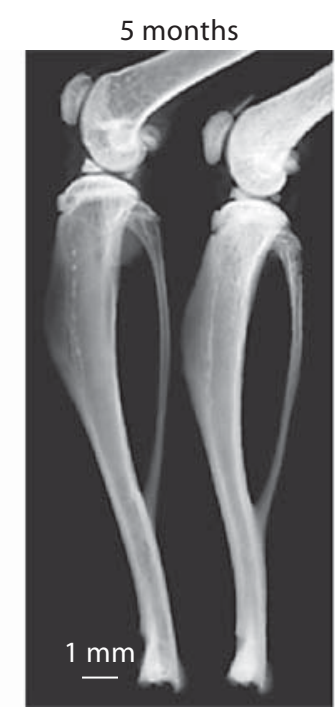

HET + DMP1 HET
Overexpression of a 57-kDa fragment

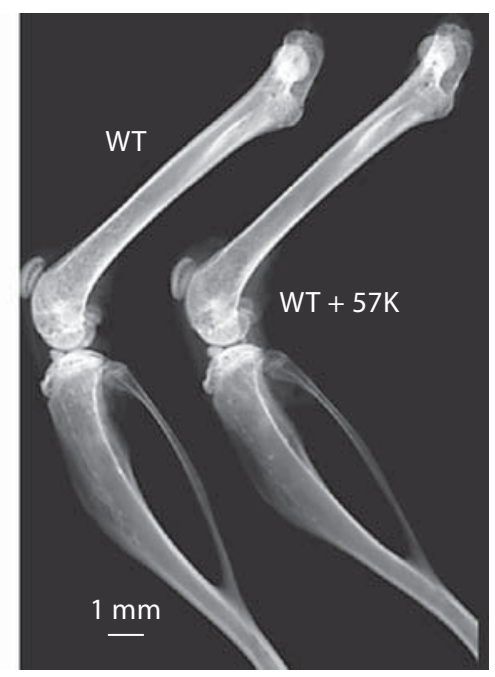

b

Fig. 5. Effects of overexpression of either the full-length DMP1 or a 57-kDa fragment using the Colla1 promoter in wild-type mice. a Overexpression of full-length DMP1. Representative radiographs of tibiae show no apparent phenotype in Dmp1-heterozygous mice overexpressing Colla1-DMP1 transgene (HET+DMP1), compared to the age-matched Dmp1 heterozygous mice (HET) at ages of 1, 2 and 5 months. b Overexpression of a $57-\mathrm{kDa}$ fragment. Radiographs show no apparent phenotype in the lower limbs from 3-month-old Colla1-57K transgenic mice $(\mathrm{WT}+57 \mathrm{~K})$, compared to those from the wild-type mice (WT) in the same litter. 


\section{Col1a1-DMP1 transgene expression}

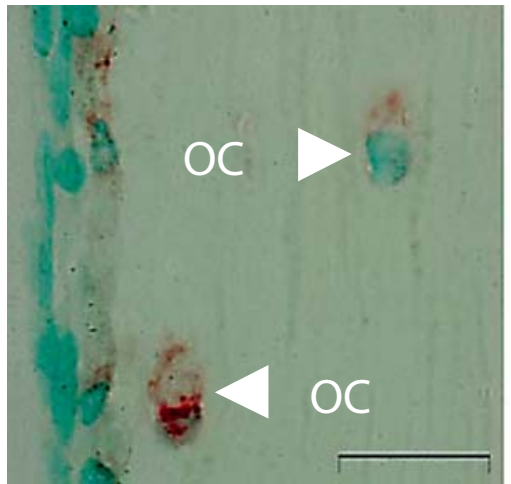

HET

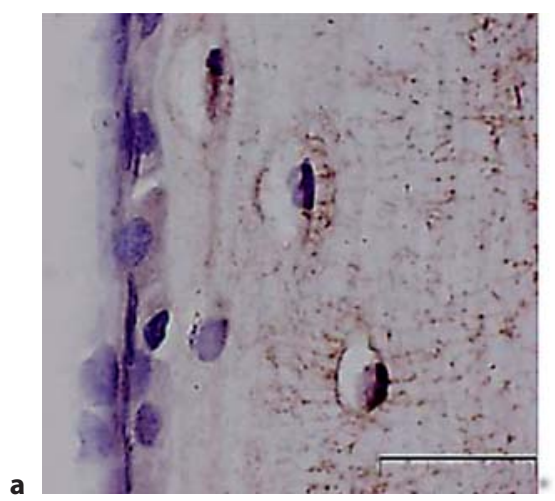

Col1 1 1-57K transgene expression

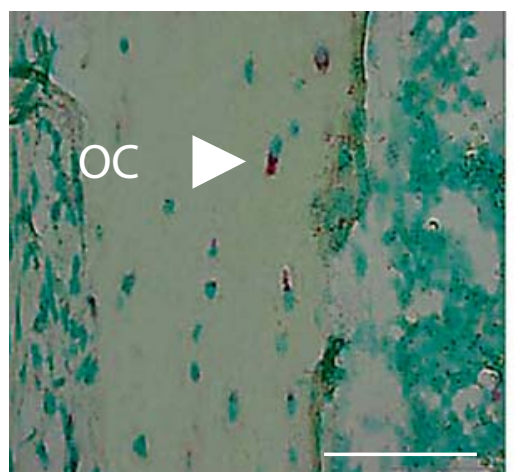

HET
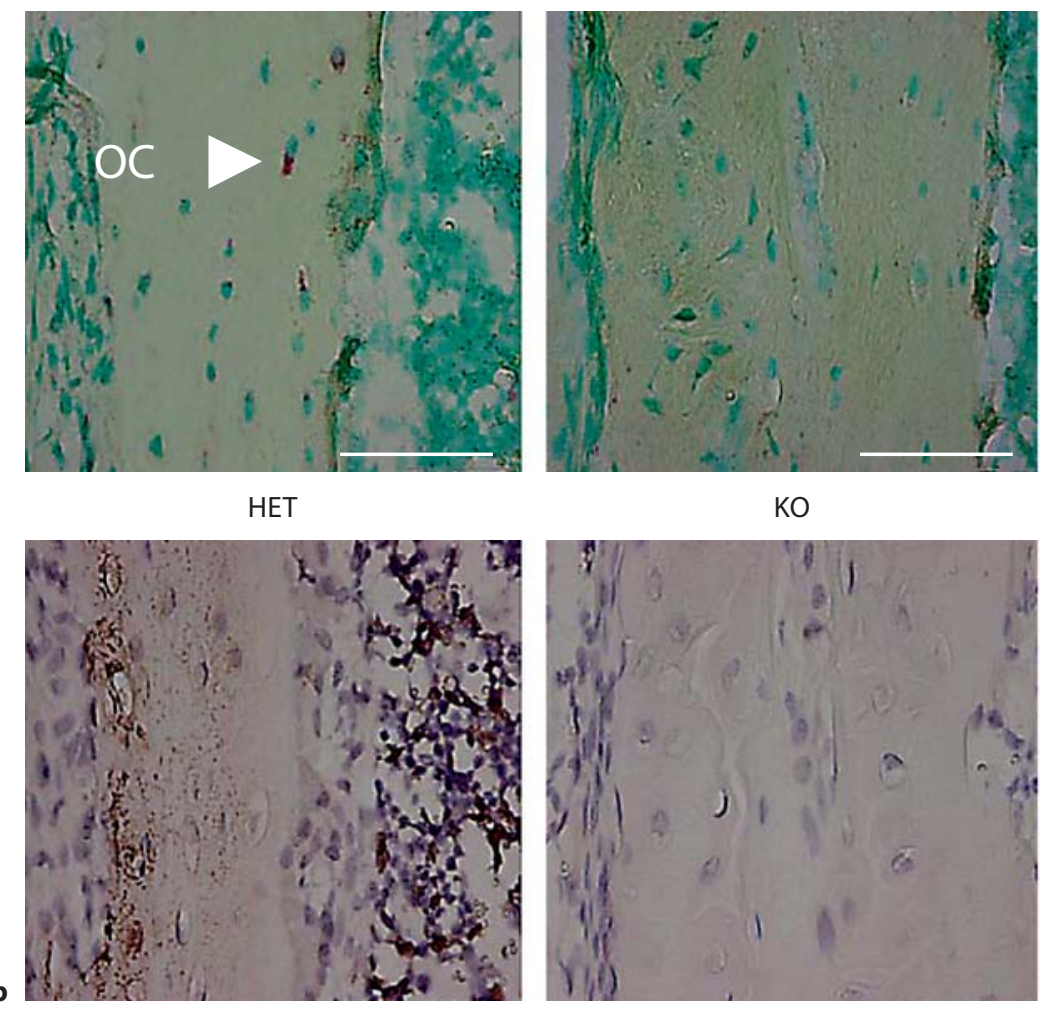

$\mathrm{KO}$

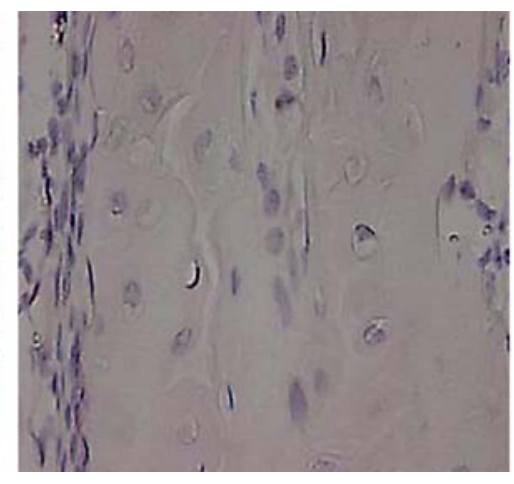

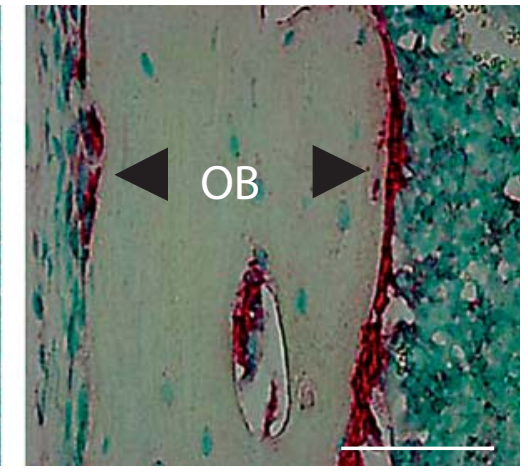

$\mathrm{KO}+57 \mathrm{~K}$

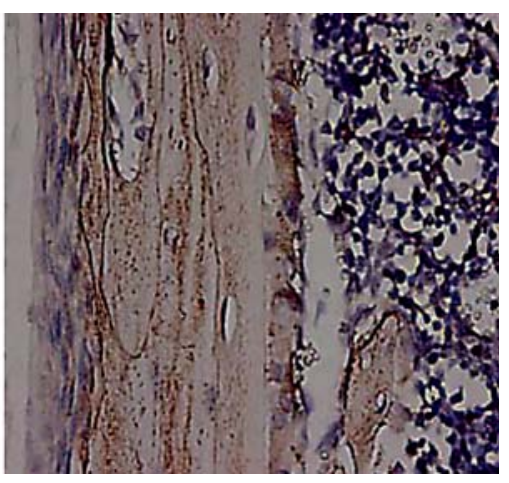

Lu/Qin/Xie/Bonewald/Feng

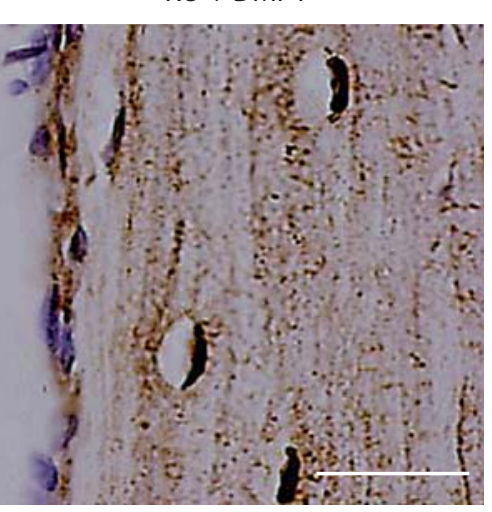


on the wild-type background displayed no apparent phenotype, as determined by radiographic examination of long bone (fig. 5). One possible explanation for this lack of effect could be that although DMP1 is required for normal skeletogenesis, the actual amount of DMP1 is not the limiting factor, but the presence of receptors or expression of upstream regulatory or downstream target molecules may be the limiting factor.

Next, the expression of the Col1a1-DMP1 or the Colla1-57K transgene at both the mRNA and protein level was determined (fig. 6). These data confirmed expression in the osteoblast lineage on the Dmp1-null background and showed that expression of the transgene was actually higher than expression of the endogenous Dmp1 gene (fig. 6). Transgene expression was highly elevated in osteoblasts on the bone surface compared to endogenous expression mainly in osteocytes in the wild-type bone. However, protein expression was elevated on the bone surface and in a lamellar pattern in the bone matrix unlike low or no expression in the osteoblast layer with protein expression along osteocyte canaliculi in wild-type bone. Preliminary data suggest that the $57-\mathrm{kDa}$ fragment may rescue the Dmp1-null phenotype (data not shown).

\section{Discussion}

In this study, we first demonstrated that the recombinant full-length DMP1 was partially processed into a 37$\mathrm{kDa} \mathrm{N}$-terminal and a $57-\mathrm{kDa}$ C-terminal fragment in

Fig. 6. Reexpression patterns of either full-length DMP1 or a 57$\mathrm{kDa}$ fragment in Dmpl-null mice using the Collal promoter. Colla1-DMP1 (a) or Colla1-57K (b) transgene expression was analyzed in tibiae from 3-week-old mice by in situ hybridization (upper panels in $\mathbf{a}$ and $\mathbf{b}$ ) and immunohistochemistry (lower panels in $\mathbf{a}$ and $\mathbf{b}$ ). Both in situ hybridization and immunohistochemistry showed that expression of endogenous DMP1 in Dmp1 heterozygous mice (HET) was found predominantly in the osteocytes (OC, white arrowheads) embedded in the bone matrix. No expression of endogenous DMP1 was detected in Dmp1-null mice (KO). In situ hybridization showed that both transgenes were highly expressed in osteoblasts (OB, black arrowheads). Immunohistochemical staining showed DMP1 protein was expressed in the canaliculi in the bone matrix in Dmp1-heterozygous mice and, as expected, there was no expression in the Dmp1-null mouse bone. However, DMP1 protein was highly expressed in the osteoblast layer and in lamellae within the bone in the 2 DMP1 transgenic mice, full-length DMP1 (KO+DMP1) or a $57-\mathrm{kDa}$ fragment $(\mathrm{KO}+57 \mathrm{~K})$. a Scale bars $=20 \mu \mathrm{m} . \mathbf{b}$ Scale bars $=50 \mu \mathrm{m}$.

Generation of 3.6-kb Colla1-DMP1 and

57-kDa Transgenic Mice
293EBNA cells, and completely cleaved into these 2 fragments in $2 \mathrm{~T} 3$ osteoblast cells and CHO cells. This processing was completely blocked when the residue at a conserved cleavage site (aspartic acid residue at position 197) was mutated to alanine. These findings not only support the DMP1 cleavage hypothesis [Qin et al., 2003], but also support the hypothesis that the protease(s) responsible for DMP1 cleavage is not tissue specific, that is, the cleavage may occur in several nonbone cell types.

Recently, bone morphogenetic protein 1 (BMP1)/tolloid-like proteinases have been shown to cleave recombinant murine DMP1 to generate fragments similar to those previously isolated from rat long bone [Qin et al., 2003; Steiglitz et al., 2004]. Interestingly, BMP1 is synthesized as an inactive proenzyme (pro-BMP1), which comprises a signal peptide, a prodomain, a catalytic domain and protein interaction domains [Bond and Beynon, 1995]. The removal of the prodomain is required for the activation of pro-BMP1 into active BMP1. The prodomain is removed by a furin-like proprotein convertase in the trans-Golgi network, which can be blocked by DEC [Leighton and Kadler, 2003]. In this study, it was confirmed that recombinant murine DMP1 was cleaved into fragments in osteoblastic 2T3 cells and nonosteoblastic $\mathrm{CHO}$ cells. This cleavage process was blocked by DEC in a dose-dependent manner. This work supports the hypothesis that a furin-like proprotein convertase activates pro-BMP1 into active BMP1, which subsequently cleaves DMP1.

Accumulating evidence supports the hypothesis that PHEX may be the protease responsible for DMP1 cleavage to generate the $57-\mathrm{kDa}$ C-terminal fragment. First, both PHEX and DMP1 are expressed in osteoblasts and osteocytes in bone. Second, Hyp mice and Dmp1-null mice manifest similar hypophosphatemic rickets/osteomalacia-like phenotypes. However, coexpression of both proteins in 293EBNA cells had no effect on DMP1 processing. This finding suggests that protease(s) other than PHEX cleave DMP1 into 2 fragments, but it cannot be excluded that other factor(s) may be required for PHEX to process DMP1 under normal physiological conditions.

Although overexpression of either a full-length DMP1 or a $57-k D a$ C-terminal fragment had no apparent effect on the skeleton, our preliminary data showed that reexpression of either transgene in Dmp1-null mice appears to rescue the skeletal abnormalities as well as the abnormal serum biochemical profile (data not shown). Detailed characterization of these mice is underway.

Cells Tissues Organs 2009;189:175-185 
In summary, the current findings suggest that DMP1 is a proprotein which is most likely cleaved in the cell. However, this cleavage process is not tissue specific and PHEX may not be required. Furthermore, we have generated and characterized transgenic mice overexpressing the full-length and the $57-\mathrm{kDa}$ fragment of DMP1 under the control of the $3.6-\mathrm{kb}$ Coll promoter separately. These transgenes are highly active in osteoblasts/ osteocytes but wild-type mice overexpressing these transgenes display no apparent phenotype, suggesting that the cleavage of DMP1 may not be a self-regulating step.

\section{Acknowledgement}

This work was supported by NIH grants AR051587 (J.Q.F.), DE005092 (C.Q.) and PO1 AR46798 (L.F.B. and J.Q.F.).

\section{References}

Bai, X., D. Miao, J. Li, D. Goltzman, A.C. Karap lis (2004) Transgenic mice overexpressing human fibroblast growth factor 23 (R176Q) delineate a putative role for parathyroid hormone in renal phosphate wasting disorders. Endocrinology 145: 5269-5279.

Beck, L., Y. Soumounou, J. Martel, G. Krishnamurthy, C. Gauthier, C.G. Goodyer, H.S. Tenenhouse (1997) Pex/PEX tissue distribution and evidence for a deletion in the $3^{\prime}$ region of the Pex gene in X-linked hypophosphatemic mice. J Clin Invest 99: 1200-1209.

Benet-Pages, A., B. Lorenz-Depiereux, H. Zischka, K.E. White, M.J. Econs, T.M. Strom (2004) FGF23 is processed by proprotein convertases but not by PHEX. Bone 35: 455462.

Bergeron, F., R. Leduc, R. Day (2000) Subtilaselike pro-protein convertases: from molecular specificity to therapeutic applications. J Mol Endocrinol 24: 1-22.

Bond, J.S., R.J. Beynon (1995) The astacin family of metalloendopeptidases. Protein Sci 4: 1247-1261.

Bowe, A.E., R. Finnegan, S.M. Jan de Beur, J. Cho, M.A. Levine, R. Kumar, S.C. Schiavi (2001) FGF-23 inhibits renal tubular phosphate transport and is a PHEX substrate. Biochem Biophys Res Commun 284: 977981.

Campos, M., C. Couture, I.Y. Hirata, M.A. Juliano, T.P. Loisel, P. Crine, L. Juliano, G. Boileau, A.K. Carmona (2003) Human recombinant endopeptidase PHEX has a strict $\mathrm{S1}^{\prime}$ specificity for acidic residues and cleaves peptides derived from fibroblast growth factor-23 and matrix extracellular phosphoglycoprotein. Biochem J 373: 271-279.

Denault, J., L. Bissonnette, J. Longpre, G. Charest, P. Lavigne, R. Leduc (2002) Ectodomain shedding of furin: kinetics and role of the cysteine-rich region. FEBS Lett 527: 309314.

Denault, J.B., A. Claing, P. D’Orleans-Juste, T. Sawamura, T. Kido, T. Masaki, R. Leduc (1995) Processing of proendothelin-1 by human furin convertase. FEBS Lett 362: 276280.
Eicher, E.M., J.L. Southard, C.R. Scriver, F.H. George, A., R. Silberstein, A. Veis (1995) In situ Glorieux (1976) Hypophosphatemia: mouse model for human familial hypophosphatemic (vitamin D-resistant) rickets. Proc Natl Acad Sci USA 73: 4667-4671.

Feng, J.Q., J. Zhang, S.L. Dallas, Y. Lu, S. Chen, X. Tan, M. Owen, S.E. Harris, M. MacDougall (2002) Dentin matrix protein 1, a target molecule for Cbfa1 in bone, is a unique bone marker gene. J Bone Miner Res 17: 18221831.

Feng, J.Q., H. Huang, Y. Lu, L. Ye, Y. Xie, T.W. Tsutsui, T. Kunieda, T. Castranio, G. Scott, L.B. Bonewald, Y. Mishina (2003) The Dentin matrix protein 1 (Dmp1) is specifically expressed in mineralized, but not soft, tissues during development. J Dent Res 82: 776-780.

Feng, J.Q., L.M. Ward, S. Liu, Y. Lu, Y. Xie, B. Yuan, X. Yu, F. Rauch, S.I. Davis, S. Zhang, H. Rios, M.K. Drezner, L.D. Quarles, L.F. Bonewald, K.E. White (2006) Loss of DMP1 causes rickets and osteomalacia and identifies a role for osteocytes in mineral metabolism. Nat Genet 38: 1310-1315.

Fisher, L.W., D.A. Torchia, B. Fohr, M.F. Young, N.S. Fedarko (2001) Flexible structures of SIBLING proteins, bone sialoprotein, and osteopontin. Biochem Biophys Res Commun 280: 460-465.

Gajjeraman, S., K. Narayanan, J. Hao, C. Qin, A. George (2007) Matrix macromolecules in hard tissues control the nucleation and hierarchical assembly of hydroxyapatite. J Biol Chem 282: 1193-1204.

George, A., J. Gui, N.A. Jenkins, D.J. Gilbert, N. G. Copeland, A. Veis (1994) In situ localization and chromosomal mapping of the AG1 (Dmp1) gene. J Histochem Cytochem 42: 1527-1531.

George, A., B. Sabsay, P.A. Simonian, A. Veis (1993) Characterization of a novel dentin matrix acidic phosphoprotein: Implications for induction of biomineralization. J Biol Chem 268: 12624-12630. hybridization shows Dmp1 (AG1) to be a developmentally regulated dentin-specific protein produced by mature odontoblasts. Connect Tissue Res 33: 67-72.

Hirst, K.L., K. Ibaraki-O'Connor, M.F. Young, M.J. Dixon (1997) Cloning and expression analysis of the bovine dentin matrix acidic phosphoprotein gene. J Dent Res 76: 754760.

Kalajzic, I., Z. Kalajzic, M. Kaliterna, G. Gronowicz, S.H. Clark, A.C. Lichtler, D. Rowe (2002) Use of type I collagen green fluorescent protein transgenes to identify subpopulations of cells at different stages of the osteoblast lineage. J Bone Miner Res 17: 15-25.

Kulkarni, G.V., B. Chen, J.P. Malone, A.S. Narayanan, A. George (2000) Promotion of selective cell attachment by the RGD sequence in dentine matrix protein 1. Arch Oral Biol 45: 475-484.

Larsson, T., R. Marsell, E. Schipani, C. Ohlsson, O. Ljunggren, H.S. Tenenhouse, H. Juppner, K.B. Jonsson (2004) Transgenic mice expressing fibroblast growth factor 23 under the control of the $\alpha 1(\mathrm{I})$ collagen promoter exhibit growth retardation, osteomalacia, and disturbed phosphate homeostasis. Endocrinology 145: 3087-3094

Leighton, M., K.E. Kadler (2003) Paired basic/ Furin-like proprotein convertase cleavage of Pro-BMP-1 in the trans-Golgi network. J Biol Chem 278: 18478-18484.

Ling, Y., H.F. Rios, E.R. Myers, Y. Lu, J.Q. Feng, A.L. Boskey (2005) DMP1 depletion decreases bone mineralization in vivo: an FTIR imaging analysis. J Bone Miner Res 20: 21692177.

Liu, S., R. Guo, L.G. Simpson, Z.S. Xiao, C.E. Burnham, L.D. Quarles (2003) Regulation of fibroblastic growth factor 23 expression but not degradation by PHEX. J Biol Chem 278: 37419-37426

Liu, S., R. Guo, Q. Tu, L.D. Quarles (2002) Overexpression of Phex in osteoblasts fails to rescue the Hyp mouse phenotype. J Biol Chem 277: 3686-3697. 
- Liu, S., J. Zhou, W. Tang, X. Jiang, D.W. Rowe, L.D. Quarles (2006) Pathogenic role of Fgf23 in Hyp mice. Am J Physiol 291: E38-E49.

Lu, Y., L. Ye, S. Yu, S. Zhang, Y. Xie, M.D. McKee, Y.C. Li, J. Kong, J.D. Eick, S.L. Dallas, J.Q. Feng (2007) Rescue of odontogenesis in Dmp1-deficient mice by targeted re-expression of DMP1 reveals roles for DMP1 in early odontogenesis and dentin apposition in vivo. Dev Biol 303: 191-201.

MacDougall, M., B.R. DuPont, D. Simmons, R.J Leach (1996) Assignment of DMP1 to human chromosome 4 band q21 by in situ hybridization. Cytogenet Cell Genet 74: 189.

-MacDougall, M., T.T. Gu, X. Luan, D. Simmons, J. Chen (1998) Identification of a novel isoform of mouse dentin matrix protein 1: spatial expression in mineralized tissues. J Bone Miner Res 13: 422-431.

-Miao, D., X. Bai, D. Panda, M. McKee, A. Karaplis, D. Goltzman (2001) Osteomalacia in hyp mice is associated with abnormal phex expression and with altered bone matrix protein expression and deposition. Endocrinology 142: 926-939.

-Narayanan, K., A. Ramachandran, J. Hao, G. He, K.W. Park, M. Cho, A. George (2003) Dual functional roles of dentin matrix protein 1: implications in biomineralization and gene transcription by activation of intracellular $\mathrm{Ca}^{2+}$ store. J Biol Chem 278: 17500-17508.
Qin, C., O. Baba, W.T. Butler (2004) Post-translational modifications of sibling proteins and their roles in osteogenesis and dentinogenesis. Crit Rev Oral Biol Med 15: 126-136.

Qin, C., J.C. Brunn, R.G. Cook, R.S. Orkiszewski, J.P. Malone, A. Veis, W.T. Butler (2003) Evidence for the proteolytic processing of dentin matrix protein 1 . Identification and characterization of processed fragments and cleavage sites. J Biol Chem 278: 34700-34708.

Quarles, L.D. (2003) FGF23, PHEX, and MEPE regulation of phosphate homeostasis and skeletal mineralization. Am J Physiol 285: E1-E9.

Rowe, P.S. (2004) The wrickkened pathways of FGF23, MEPE and PHEX. Crit Rev Oral Biol Med 15: 264-281.

Ruchon, A.F., H.S. Tenenhouse, M. Marcinkiewicz, G. Siegfried, J.E. Aubin, L. DesGroseillers, P. Crine, G. Boileau (2000) Developmental expression and tissue distribution of Phex protein: effect of the Hyp mutation and relationship to bone markers. J Bone Miner Res 15: 1440-1450.

Shimada, T., H. Hasegawa, Y. Yamazaki, T. Muto, R. Hino, Y. Takeuchi, T. Fujita, K. Nakahara, S. Fukumoto, T. Yamashita (2004a) FGF-23 is a potent regulator of vitamin D metabolism and phosphate homeostasis. J Bone Miner Res 19: 429-435.

-Shimada, T., M. Kakitani, Y. Yamazaki, H. Hasegawa, Y. Takeuchi, T. Fujita, S. Fukumoto, K. Tomizuka, T. Yamashita (2004b) Targeted ablation of Fgf23 demonstrates an essential physiological role of FGF23 in phosphate and vitamin D metabolism. J Clin Invest 113: 561-568.
Steiglitz, B.M., M. Ayala, K. Narayanan, A. George, D.S. Greenspan (2004) Bone morphogenetic protein-1/Tolloid-like proteinases process dentin matrix protein-1. J Biol Chem 279: 980-986.

Tartaix, P.H., M. Doulaverakis, A. George, L.W. Fisher, W.T. Butler, C. Qin, E. Salih, M. Tan, Y. Fujimoto, L. Spevak, A.L. Boskey (2004) In vitro effects of dentin matrix protein-1 on hydroxyapatite formation provide insights into in vivo functions. J Biol Chem 279: 18115-18120.

Tenenhouse, H.S., Y. Sabbagh (2002) Novel phosphate-regulating genes in the pathogenesis of renal phosphate wasting disorders. Pflugers Arch 444: 317-326.

Toyosawa, S., S. Shintani, T. Fujiwara, T. Ooshima, A. Sato, N. Ijuhin, T. Komori (2001) Dentin matrix protein 1 is predominantly expressed in chicken and rat osteocytes but not in osteoblasts. J Bone Miner Res 16: 20172026.

>Ye, L., Y. Mishina, D. Chen, H. Huang, S.L. Dallas, M.R. Dallas, P. Sivakumar, T. Kunieda, T.W. Tsutsui, A. Boskey, L.F. Bonewald, J.Q. Feng (2005) Dmp1-deficient mice display severe defects in cartilage formation responsible for a chondrodysplasialike phenotype. J Biol Chem 280: 61976203. 